
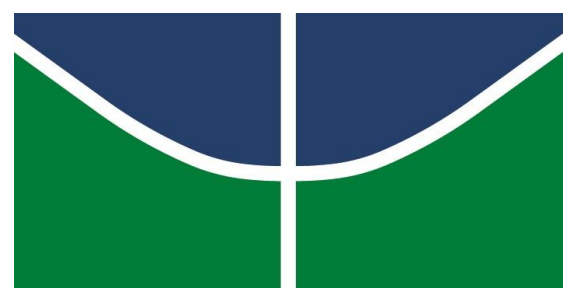

Universidade de Brasília

Faculdade de Comunicação

Comunicação Social - Comunicação Organizacional

O diálogo possível: as contribuições da Comunicação Organizacional para a Biblioteca Ministro Oscar Saraiva

Autora: Mônia Zoraima Câmara Magalhães

Orientadora: Profa. Dra. Elen Cristina Geraldes

Brasília, DF

$1 \% / 2017$ 
Memorial do artigo "O diálogo possível: as contribuições da Comunicação Organizacional para a Biblioteca Ministro Oscar Saraiva" apresentado à Faculdade de Comunicação da Universidade de Brasília como requisito parcial para obtenção do grau de bacharel em Comunicação Social, habilitação em Comunicação Organizacional 
Resumo: Este memorial apresenta o processo de produção do artigo O diálogo possível: as contribuições da Comunicação Organizacional para a Biblioteca Ministro Oscar Saraiva, que tem como objetivo discutir as semelhanças e diferenças nas duas áreas do conhecimento e propor sugestões e recomendações para a biblioteca do Superior Tribunal de Justiça. Narra o processo desde as matérias cursadas ao longo do curso e a trajetória profissional, que desembocaram na escolha do tema, até o caminho metodológico percorrido para alcançar os objetivos pretendidos, apontando as dificuldades e conquistas com a ajuda do referencial teórico e da coleta de dados.

Palavras-chave: Artigo. Memorial. Comunicação Organizacional. Biblioteconomia.

\begin{abstract}
This memorial presents the production process of the article the possible dialogue: the contributions of the Organizational Communication to the Library Minister Oscar Saraiva, whose objective is to discuss the similarities and differences in the two areas of knowledge and to propose suggestions and recommendations for the library of the Superior Tribunal Justice. It narrates the process from the subjects taken along the course and the professional trajectory, which resulted in the choice of the theme, to the methodological path taken to reach the desired objectives, pointing out the difficulties and achievements with the help of theoretical reference and data collection.
\end{abstract}

Keywords: Article. Memorial. Organizational Communication. Librarianship. 


\section{O começo}

A minha história com o curso Comunicação Organizacional começou bem antes de 2012, ano que ingressei na Faculdade para cursá-lo.

Fui criada em uma cidade mineira chamada Paracatu e lá é tradição os estudantes terminarem o ensino médio e irem estudar fora, em cidades com universidades renomadas. Ser aprovado em vestibulares de universidades públicas é a maior conquista que um estudante pode alcançar no alto dos seus 17, 18 anos.

Por sempre ter estudado em escola privada, em casa a pressão era enorme. Só moraria fora se passasse em universidade pública. E como escolher o meu curso ou como escolher a minha profissão e o meu futuro? Na incerteza dessa escolha, o medo de não ser aprovada e o sonho de morar sozinha em outra cidade, marquei Biblioteconomia na inscrição do vestibular.

Biblio o quê? Biblioteconomia, o curso que organiza bibliotecas, que tem grandes oportunidades de trabalho, que é para quem gosta de ler e não é muito concorrido. Essa era a resposta que eu dava para as perguntas que surgiam e o mantra que eu repetia todos os dias para validar a minha escolha. Em casa, o sonho de ver uma filha formada duelava com a escolha do curso, meus pais nunca se opuseram com a minha escolha, mas, talvez, se questionavam se era isso que eu queria para mim. "Você é muito nova, minha filha, tem a vida inteira para fazer outros cursos."

E assim, em março de 2015, começou a minha jornada de estudante de Biblioteconomia na Universidade de Brasília. Tinha 17 anos e tudo era novidade e me encantava, só que faltava algo que eu nunca soube o que era. Vieram as matérias específicas, a convivência com os colegas, os estágios e a certeza que eu queria mais.

O curso de Biblioteconomia foi um curso bem técnico, aprendi regras de classificação, catalogação, indexação, pode isso, não pode aquilo. Realmente, o curso é muito bom em questões de estágio e mercado de trabalho. Comecei a estagiar no segundo semestre e desde então sempre estive empregada.

Lembro que olhava admirada para as minhas professoras que também chefiavam bibliotecas e pensava: é isso que eu quero. Não quero trabalhar no fundo da biblioteca sem ver ninguém, além dos colegas de trabalho, quero estar em contato com o público. No meu estágio no Superior Tribunal de Justiça fui selecionada para trabalhar em um gabinete, era responsável pela biblioteca particular do Ministro. A minha mesa de trabalho era na secretaria 
do gabinete e logo comecei a ajudá-los com atendimento. Foi ali que percebi que o que eu queria de verdade era a comunicação, a interação, o reconhecimento.

Com 21 anos estava formada, com um diploma da UnB e empregada. Trabalhei em biblioteca escolar e universitária e a inquietação de que algo me faltava me acompanhava em todo esse processo. Em 2012, quatro anos depois de formada, depois de relutar muito, tomei duas decisões na minha vida. Precisava me estabilizar financeiramente e estudei para passar em um concurso e era a hora de estudar comunicação. As duas aprovações vieram seguidas, no mesmo espaço de tempo. O final do primeiro semestre de 2012 foi emocionante.

Agosto de 2012 começou a história desse memorial. Novamente caloura, agora de um curso noturno com habilitação nova e a chance de frequentar a FAC como estudante da faculdade e não apenas como estudante de Introdução à Comunicação, matéria obrigatória da Biblioteconomia. Nunca me vi jornalista, publicitária ou cineasta, com a Comunicação Organizacional surgia um novo cenário, uma nova estudante e uma nova perspectiva.

Diferentemente dos meus colegas de graduação, não precisava me preocupar com matérias optativas ou contagem de créditos por semestre, estava dedicada exclusivamente para as disciplinas obrigatórias. Como era bom ir para as aulas, me sentia revigorada com a juventude dos colegas, com o prazer que os professores ministravam as aulas, com as trocas de opinião e pelo novo mundo que se criava na minha realidade. Não sei descrever todas as matérias cursadas ao longo do curso, mas tenho memórias afetivas de algumas delas.

No primeiro semestre, na disciplina Ética, Legislação e Responsabilidade Social, com a Professora Elen, me vi desafiada em definir e ilustrar o que era ética em uma folha A3, lembro também que o trabalho final da matéria era uma resenha de um livro que a Professora dava de presente para cada aluno. O meu era sobre um conquistador do Sul e ganhei um elogio sobre a escrita.

No segundo semestre me encantei com a disciplina Planejamento em Comunicação, com a Professora Liziane. Tudo ainda muito no campo teórico de como fazer e, mesmo assim, planejamos a comunicação do Centro de Documentação da UnB - CEDOC. Teve também a disciplina com a Professora Janara, Teorias da Comunicação Organizacional, na qual o trabalho final era um seminário sobre Clima e Cultura Organizacional e na dinâmica, nosso grupo imprimiu um crachá com a foto de perfil do facebook de cada colega da sala, que representavam os funcionários da empresa, nosso grupo era o responsável pela comunicação e a Professora, a diretora.

No terceiro semestre tive mais contato com o design, assunto que nunca dominei e na disciplina Planejamento Gráfico, Visual e Web, com o Professor Luciano, percebi que tinha 
muito que aprender com as ferramentas, conceitos e maneira de criar. Criei um manual de identidade visual para a colega de classe, escrevi 50 vezes o meu nome com tipografias diferentes e no final criamos um infográfico sobre as novelas mexicanas. Já na disciplina Gestão em Comunicação com a Professora Liziane, realizamos a gestão de crise da apresentadora Xuxa, que naquela época, tinha sido ofendida no Senado Federal e gerado grande repercussão.

Escrevendo esse memorial identifico nos três primeiros semestres do curso uma sequência de disciplinas teóricas que foram fundamentais para fincar os conceitos e nos preparar para os semestres finais que foram muito mais práticos. Os três primeiros semestres nos deram base, nos ensinaram a fazer, os quatros semestres posteriores nós fizemos, colocamos em prática e o conhecimento teórico virou ação.

Quarto semestre. Divisor. A prova de fogo. Nesse momento você questiona se consegue seguir em frente e se você será um Comunicador. Acredito que todo curso tem a disciplina mais temida ou mais comentada, a disciplina que todos fantasiam, fazem dela uma lenda. Instrumento da Comunicação Organizacional é a disciplina. Ministrada pelas Professoras Elen e Janara, ICO, como é conhecida, te transforma, você deixa de ser mais um estudante e se torna o estudante de Comunicação Organizacional, você sai da sua comodidade, pensa além do óbvio, se recria e transforma a realidade de uma OnG. No meu semestre inovaram e transformamos a realidade dentro da UnB, através dos programas de extensão.

Todas as disciplinas se unificam nesse momento. Você precisa dos conhecimentos de planejamento, de marketing, de ética, de design, de produção e edição de som para gerar produtos. O nosso grupo estava inserido dentro do Programa de Portadores de Necessidades Especiais - PPNE, éramos os responsáveis pela mudança e junto com a equipe de trabalho criamos um Plano de Comunicação que contemplava a comunicação interna e externa, a definição da missão e valores, a identidade visual com a revitalização da marca em um novo logotipo e cor, a criação do vídeo institucional, a valorização da equipe e realizamos um evento com a presença do Reitor nas dependências do PPNE. ICO não foi apenas a teoria se tornando realidade através de cada produto que entregávamos, foi ensinamento para lidar com a cobrança, com a pressão, com o prazo, com a nossa ansiedade, com as dificuldades que iam surgindo, com o que saia do nosso controle e com a opinião dos jurados, porque além do peso que ICO carrega, nós também estávamos em uma competição. Ganhar o badalado Prêmio ICO te colocava em um outro patamar entre os estudantes, era como se você fosse o maioral, 
aquele que sabia fazer. Não ganhamos o prêmio, mas passamos na disciplina e vemos até hoje o nosso trabalho no PPNE gerando frutos.

Passada toda essa pressão, o quinto semestre foi mais tranquilo. Estávamos no início de 2015 e na disciplina do Professor Caíque, Roteiro, Produção e Direção para web, vídeo e cinema, críamos o vídeo 'Uma namorada para o Jonathas'. Com os Professores Asdrubal e Ellis, em Planejamento e Gestão em Org. Públicas, Privadas e do Terceiro Setor, fizemos um observatório sobre hortas comunitárias e apresentamos na sede da Embrapa.

O final do curso se aproxima e com o Professor Samuel, na disciplina Avaliação em Projetos de Comunicação, aprendemos como mensurar os resultados dos projetos que futuramente criaríamos.

No semestre que antecede a monografia, fomos assessores de comunicação na Ouvidoria da UnB. Se ICO é a prova de fogo, Assessoria e Consultoria em Comunicação é o fogo. A disciplina com o maior número de créditos da grade, lecionada por três professores, cobra do quase formando uma postura diferente. Você tem um cliente, um prazo, uma demanda, mesmo sendo estudante, não há espaço para amadorismos, a cobrança é real. É a última disciplina do curso e o momento que você lapida a sua trajetória estudantil para se tornar um formando em Comunicação Organizacional.

Finda todas as disciplinas é hora de deixar seu legado na FAC expressando através de um produto ou monografia o arcabouço teórico e vivência na faculdade. O Pré-Projeto de TCC ajuda nas delimitações do tema, na estruturação do trabalho, na pesquisa das fontes de informação, na escolha do orientador. Me vi perdida, sem tema, querendo escrever sobre tudo e sem foco, mas com a ajuda da Professora Janara fiz o Pré TCC sobre um tema bem legal e bem diferente da minha realidade.

O último semestre seria o desenvolvimento desse pré-projeto e com a ajuda do Professor Luciano comecei a ler, pesquisar e estruturar o trabalho que seria sobre a criação de um aplicativo. Com a oportunidade de estudar inglês fora do país tranquei o semestre e retomei meu projeto de TCC no semestre posterior, com a Professora Elen.

Para chegar no momento específico desse memorial preciso voltar em maio de 2015, metade do quinto semestre, quando fui nomeada para exercer o cargo de Analista do Superior Tribunal de Justiça - STJ como Bibliotecária e comecei a minha carreira profissional. Trabalho na Seção de Atendimento e Pesquisa da Biblioteca, a única seção que trabalha diretamente com o público realizando atendimentos de empréstimo, devolução, reserva, cópias reprográficas, cadastro de usuários e pesquisas de doutrina e legislação. 
A Biblioteca do STJ oferece aos seus usuários acesso a base de dados jurídicas, disseminação seletiva de informação, clipping de legislação, acervo com livros atualizados, periódicos renomados, pesquisa de doutrina e legislação, biblioteca digital entre outros produtos. Conforme ia me familiarizando com o trabalho, com a seção e com o funcionamento da Biblioteca, identificava elos entre a comunicação e a prática bibliotecária, vislumbrava os ensinamentos da faculdade sendo aplicado na divulgação dos serviços, na comunicação interna, na elaboração de políticas e no planejamento.

Atualmente, fui designada junto com uma colega de profissão para ficar responsável pela comunicação da Biblioteca e acompanhamos reuniões sobre campanhas, damos sugestões, escrevemos textos para a intranet, tudo muito experimental ainda.

Voltando para a minha linha do tempo na faculdade, no primeiro semestre 2017 procurei a Professora Elen para conversar sobre o meu projeto de TCC que eu gostaria que fosse orientado por ela, mas estava confusa quanto ao assunto. A Professora com toda a sua generosidade e acolhimento me incentivou a escrever sobre as duas áreas.

E assim nasceu o tema do projeto final do curso, um artigo científico sobre o encontro entre Biblioteconomia e Comunicação Organizacional. Um encontro entre a realização profissional e a realização pessoal. Entre um sonho e uma realidade.

\section{O meio}

De posse do tema do artigo começa a fase mais desafiante do curso para mim. Por mais prazeroso que seja produzir um trabalho, muitas vezes me vi perdida e com bloqueios para colocar no papel o que na mente borbulhava. O trabalho consome energia e tempo, não conseguia ir em todas as orientações e pensei em desistir. Foi preciso persistência e paciência para acreditar que daria certo. Tive sorte, a minha orientadora acreditou no trabalho, no tema e em mim. Obrigada, professora Elen!

$\mathrm{Na}$ primeira orientação definimos que a questão problema que o artigo tentaria responder era como a Comunicação Organizacional poderia contribuir para a prática de biblioteconomia na Biblioteca do STJ. Para alcançar o objetivo de apontar as sugestões e recomendações era preciso conceitos, características de cada área. $\mathrm{O}$ artigo começa com uma revisão de literatura sobre Comunicação Organizacional e Biblioteconomia.

A revisão de literatura é "um conjunto de procedimentos que visa identificar informações bibliográficas, selecionar documentos pertinentes ao tema estudado e proceder à respectiva anotação das referências e dos dados dos documentos utilizados na redação do 
trabalho acadêmico (STUMPF, p.51, 2009). Para embasar todo o trabalho, a revisão de literatura buscou aprofundar os conceitos de comunicação organizacional, biblioteconomia e biblioteca com a leitura de livros, artigos, monografias e dissertações publicadas nas respectivas áreas.

Kusnch $(1997,1998,1999,2003)$ e Torquato (2002) destacam-se entre os autores brasileiros, constituindo-se em referências dos estudos de comunicação organizacional. Suas obras têm sido marcadas por uma preocupação constante em estabelecer a abrangência do seu campo de atuação bem como atribuir-lhe a posição estratégica no espaço organizacional. "A comunicação organizacional deve constituir-se num setor estratégico, agregando valores e facilitando os processos interativos, por meio das Relações Públicas, da organização com os seus diferentes públicos, a opinião pública e a sociedade em geral”, afirma Kunsch. Defende a tese da Comunicação Integrada, entendendo-a como "uma filosofia que direciona a convergência das diversas áreas, permitindo uma atuação sinérgica. ” (KUNSCH, 2003, p. 150). Sob essa perspectiva pressupõe uma junção da comunicação institucional, da comunicação mercadológica, da comunicação interna e da comunicação administrativa, que formam um mix, o composto da comunicação organizacional” (KUNSCH, 2003, p. 150).

Tourquato (2002, p 35), por sua vez, afirma que a comunicação organizacional “é a possibilidade sistêmica que, integrada, reúne as modalidades de comunicação cultural, comunicação administrativa, comunicação social e sistemas de informação".

As modalidades apresentadas por esses dois autores, embora com denominações distintas, buscam dar conta da complexidade da comunicação nas (e das) organizações com seus diferentes segmentos de públicos.

Para Kunsch (1995, p.92), a comunicação institucional permite à organização "ter um conceito e um posicionamento favorável perante à opinião pública", isto é, a construção de sua credibilidade, enquanto a comunicação mercadológica volta-se para a divulgação dos produtos e serviços, compreendendo toda a manifestação gerada em torno dos objetivos de venda de uma organização. Ambas, ressalvando as suas diferenças e especificidades, implementam ações destinadas aos públicos externos da organização. Torquato (2002) engloba essas duas modalidades de comunicação sob a denominação de comunicação social na qual estão contempladas as áreas de jornalismo, relações públicas, publicidade, editoração e marketing, admitindo-a como " a mais desenvolvida, tanto do ponto de vista conceitual quanto dos pontos de vista operacional e tecnológico." (Torquato, 2002, p.34).

$\mathrm{Na}$ parte de Biblioteconomia, buscou-se contar a sua história, sua origem e seu ensino e depois conceituar o que é biblioteca. 
A palavra Biblioteconomia é composta pelos elementos gregos: biblion que significa livro; théke que significa caixa e nomos que significa regra. Etimologicamente, "biblioteconomia é o conjunto de regras de acordo com as quais os livros são organizados em espaços apropriados: estantes, salas, edifícios. " (FONSECA, 2007, p.1)

Portanto, não há como contar a história da biblioteconomia sem mencionar a história das bibliotecas e seus processos de organização e preservação de documentos.

A Biblioteca de Elba, na Síria, data do terceiro milênio a.C. e é considerada a primeira biblioteca primitiva com um acervo organizado em estantes e por assunto. A Biblioteca de Alexandria, considerada uma das maiores bibliotecas da Antiguidade, tinha seu acervo constituído pelos livros copiados de todos os navios que paravam na cidade, com a intenção de abrigar todo o conhecimento humano registrado.

$\mathrm{Na}$ Idade Média as bibliotecas ligadas às ordens religiosas eram predominantes e responsáveis pela preservação da cultura greco-romana. Nessa época surgem as bibliotecas das universidades e os grandes colecionadores de livros. Com a tecnologia da impressão inventada por Gutenberg em 1440, a biblioteca deixa de ser responsável pela reprodução dos documentos e se distancia dos processos de organização e compreensão dos conteúdos.

Durante a Idade Antiga e a Idade Média, museus, arquivos e bibliotecas constituíam a mesma entidade porque organizavam e armazenavam todo tipo de documento. Permaneceu inalterada até a Idade Moderna quando as bibliotecas passaram a existir separadamente e ganharam a maior visibilidade pública e social. Surge, então, o conceito de biblioteca pública moderna, constituída de acervos gerais de livros e aberta gratuitamente ao público em horários regulares.

Com o surgimento das bibliotecas públicas, o aumento da produção bibliográfica e o crescimento dos periódicos e sua importância na divulgação cientifica, cresce a necessidade de novas ferramentas de organização, preservação e recuperação das coleções e alguns teóricos apresentam relevante contribuição na busca desses métodos.

No Brasil não há uma data específica ou um momento certo que defina o início da Biblioteconomia. Alguns pesquisadores consideram a partir da Biblioteca Nacional, quando o Brasil conquista sua independência política. Carvalho (2010) faz uma abordagem a partir das bibliotecas coloniais considerando uma marca importante para o surgimento do ensino da biblioteconomia no país.

A Biblioteconomia no Brasil se desenvolveu com a vinda da Coroa Portuguesa para o país e a modernização da cidade do Rio de Janeiro, que se tornou a capital do Império e ganhou a primeira Biblioteca Nacional, fundada em 1810, mas aberta ao público apenas em 
1814.

Assim como no período colonial os responsáveis pelo acervo eram homens religiosos, foi Manuel Cícero Peregrino da Silva, diretor da Biblioteca Nacional, que criou o primeiro curso de Biblioteconomia do Brasil, em 1911.

O curso iniciou em 1915 e foi extinto em 1922, tinha duração de um ano e quatro disciplinas: Bibliografia, Paleografia e Diplomática, Iconografia e Numismática, que eram as mesmas seções da Biblioteca e os professores eram os chefes de cada seção. Após 11 anos, em 1933 o curso foi reiniciado com algumas mudanças: a duração de dois anos e a inclusão da disciplina História Literária aplicada à Bibliografia. O grande foco do curso da Biblioteca Nacional era "dar ênfase especial ao aspecto cultural e informativo, preocupando-se menos com o enfoque técnico". (TARAPANOFF, 2006, p. 48).

De acordo com o Conselho Nacional de Desenvolvimento Científico e Tecnológico (CNPq), a Biblioteconomia se enquadra na área de Ciências Sociais e Aplicadas. Como uma área do conhecimento científico que lida com o fluxo da informação, e potencialmente com a educação não-formal, a Biblioteconomia deve trabalhar sob uma perspectiva local e global: a serviço da comunidade em que se insere a unidade de informação (comunidade acadêmica, população de um bairro, de uma escola etc.), visando ao benefício da sociedade e humanidade, por meio da cooperação de unidades de informação entre si e com a comunidade.

O avanço da tecnologia e as grandes mudanças culturais estão alterando os modelos biblioteconômicos de ensino e atuação profissional, visualizados também pela terminologia da área, de Ciência da Biblioteca, a Biblioteconomia tem convivido com o modelo da Ciência da Informação, em que o foco passa da manutenção e organização do acervo e de suportes da informação para o usuário e a disseminação da informação.

Já a história da biblioteca é a história do registro da informação. O homem sempre criou formas para registrá-la, mesmo que rudimentares, para não dispersar o conhecimento. É preciso reter a informação sobre algum suporte concreto, preservar e organizá-la. Quanto mais conhecimento produzido, mais a exigência de controle.

O bibliotecário que apenas organizava os livros agora precisa organizar a informação, analisando cada documento para descobrir o conteúdo que o torna registrável e recuperável. Guardar volumes nas estantes pelo assunto não atende mais o novo usuário, que agora exige assuntos específicos.

Assim, cada biblioteca atende a um determinado público. O usuário pode ser um adulto em processo de alfabetização ou um pesquisador com interesse em acompanhar os 
avanços científicos do seu setor. Quanto mais direcionado o assunto, mais seleto será o acervo e maiores as possibilidades de controle informativo.

Para Cesarino (1979, p.231), as bibliotecas especializadas são "unidades pertencentes a instituições governamentais, particulares ou associações formalmente organizadas com o objetivo de fornecer ao usuário a informação relevante de que ele necessita, em um campo específico do conhecimento. "Disseminam os conhecimentos necessários nos estudos e tomadas de decisões das instituições das quais fazem parte e possuem um acervo seletivo, atualizado, personalizado, especializado e com difusão seletiva.

Para atender os seus usuários com elevado nível de formação e exigentes em suas pesquisas, as bibliotecas especializadas precisam fornecer informações de forma rápida e eficaz; realizar tratamento exaustivo nos documentos para ampliar os recursos de recuperação da informação, disseminar seletivamente a informação e proporcionar o acesso a base de dados especializadas nas áreas de interesse.

\section{O meio do meio}

Feita a revisão de literatura é hora de analisar e propor por meio de sugestões quais seriam as contribuições de uma área para a prática da outra. Por trabalhar diariamente na biblioteca, tive acesso a relatórios, dados e estatísticas, facilitando a observação in loco, que foi feita baseada na metodologia do estudo de caso.

O estudo da Comunicação Organizacional pode ser um meio para bibliotecários adquirirem a compreensão, não só do entendimento da estrutura administrativa implícita à biblioteca, como também dos mecanismos de integração formal dessa estrutura com a instituição que a sustenta e com os públicos que interagem.

O objetivo geral deste artigo é tentar solucionar a seguinte questão-problema: Como a Comunicação Organizacional pode contribuir para as práticas de biblioteconomia na Biblioteca Ministro Oscar Saraiva? Por objetivo específico, pretende apontar sugestões e recomendações.

Dividimos o artigo em quatro partes. Na primeira, apresentei a área de Comunicação Organizacional com as suas principais linhas e tendências de pesquisa. Na segunda, defini e conceituei Biblioteconomia e Biblioteca. Na terceira parte, apresentei a metodologia utilizada e descrevei a observação. Por fim, fiz a análise dos resultados.

O estudo de caso "é uma inquirição empírica que investiga um fenômeno contemporâneo dentro de um contexto da vida real, quando a fronteira entre o fenômeno e o 
contexto não é claramente evidente e onde múltiplas fontes de evidência são utilizadas. É a estratégia preferida quando é preciso responder a questões do tipo 'como' e 'por que' e o pesquisador tem pouco controle sobre os eventos e quando o foco se encontra em fenômenos contemporâneos inseridos em algum contexto da vida real. " (YAN apud DUARTE, 2009, p.216)

Para entender a complexidade de muitas situações, a participação direta e a observação do fenômeno de interesse pode ser o melhor método de pesquisa. Na observação participante, o observador coloca-se na posição dos observados, devendo inserir-se no grupo a ser estudado como se fosse um deles, pois assim tem mais condições de compreender os hábitos, atitudes, interesses, relações pessoais e características do funcionamento daquele grupo (BARDIN, 1997). Isso requer que o observador se torne parte do universo investigado para entendimento do contexto das ações e apreensão dos aspectos simbólicos que o permeiam (PROENÇA, 2008).

$\mathrm{Na}$ análise optei por dividir as atividades da biblioteca de acordo com a cadeia documental, que é o conjunto de todas as ações que ocorrem em uma biblioteca desde a seleção de uma obra até a disposição nas estantes para o usuário, separados em quatro processos: formação e desenvolvimento, organização, dinamização do uso das coleções e funções gerenciais. As atividades específicas de cada grande processo foram descritas e contextualizadas com o modus operante da biblioteca para depois sugerir quais seriam os instrumentos de comunicação que contribuiriam para melhorar, aperfeiçoar ou valorizar cada atividade.

O artigo se encerra com as considerações finais onde apresento de forma sucinta todo o processo e os resultado da análise.

\section{O fim}

O artigo cientifico é a apresentação dos resultados de estudos realizados a respeito de uma questão. O objetivo principal é ser um canal rápido e sucinto de divulgar e tornar conhecida, através de sua publicação em periódicos especializados das duas áreas do conhecimento ou como capítulo de um livro, a dúvida investigada, o referencial teórico utilizado, a metodologia empregada, os resultados alcançados e principais dificuldades encontradas na análise de uma questão.

Esse memorial foi escrito para contar como se deu o processo de elaboração do meu artigo apresentado à Faculdade de Comunicação como requisito parcial para obtenção do grau 
de bacharel em Comunicação Social, habilitação em Comunicação Organizacional.

Não foi fácil. Nunca é. Se fosse, não teria graça. Concluir essa etapa me enche de orgulho por que reconheço meus méritos, minha coragem e minha vontade de aprender sempre um pouco mais, assim, como também reconheço que poderia ter sido uma estudante mais aplicada e organizada. O importante é perceber que nas falhas também existem acertos e por mais que eu tenha tido obstáculos para a conclusão, eu consegui.

Tentei ao máximo escrever essas páginas de uma forma fluída e leve, por que foi assim, leve, fluído e gostoso, o tempo que passei na FAC tendo aula com os melhores professores que compartilhavam conhecimento e experiência de uma forma admirável e ao lado de colegas maravilhosos, que nas diferenças me ensinaram e me rejuvenesceram.

No início do curso, o incentivo foi o comentário escrito na correção de um trabalho; na metade, ganhei um livro sobre a história de um estudante que vive em duas culturas e no final, a paciência, orientação e motivação para conclusão do artigo. O ciclo se encerra como começou: com ela reforçando minha qualidade, minha oportunidade e minha realidade. Professora Elen, obrigada pela sensibilidade quando orienta, pelo carinho quando fala e pela paciência quando leciona. 


\section{Referências}

AMARAL, Sueli Angélica do. Marketing na ciência da informação. Brasília: Editora Universidade de Brasília, 2007.

AMARAL, Sueli Angélica do. Promoção: o marketing visível da informação. Brasília: Brasília Jurídica, 2001.

BARDIN, Lawrence. Análise de conteúdo. Lisboa: Edições 70; 1997.

KUNSCH, Margarida M. Krohling. Comunicação organizacional: histórico, fundamentos e processos. São Paulo: Saraiva, 2009.

KUNSCH, Margarida M. Krohling. Comunicação organizacional: linguagem, gestão e perspectivas. São Paulo: Saraiva, 2009.

KUNSCH, Margarida M. Krohling. Relações públicas e modernidade: novos paradigmas na comunicação organizacional. São Paulo: Summus, 1997.

KUNSCH, Margarida Maria Krohling. Planejamento de relações públicas na comunicação integrada. São Paulo: Summus, 2003.

FORMIGA, Asdrubal Borges. Muito além dos meios: comunicação organizacional: desafios e interfaces. Brasília: Editora Universidade de Brasília, 2014.

NASSAR, Paulo. O que é comunicação empresarial. São Paulo: Brasiliense, 1995.

PROENÇA, Wander de Lara. O método da observação participante. Rev. Antropos, Brasília, v. 2, n. 1, p. 8-31, 2008.

QUEIROZ, Danielle Teixeira et al. Observação participante na pesquisa qualitativa: conceitos e aplicações na área da saúde. Rev. Enferm. UERJ, Rio de Janeiro, v. 15, n. 2, p. 276-283, 2007.

REGO, Francisco Gaudêncio Torquato do. Comunicação empresarial, comunicação institucional: conceitos, estratégias, sistemas, estrutura, planejamento e técnicas. 3. ed. São Paulo: Summus, 1986. 